East African Medical Journal Vol. 80 No. 1 January 2003

PRIMARY HEALTH CARE, SELECTIVE OR COMPREHENSIVE, WHICH WAY TO GO?

E.M. Obimbo, MBChB, MMed, Lecturer, Department of Paediatrics and Child Health, College of Health Sciences, University of Nairobi, P.O. Box 19676, Nairobi, Kenya

\title{
PRIMARY HEALTH CARE, SELECTIVE OR COMPREHENSIVE, WHICH WAY TO GO?
}

\author{
E.M. OBIMBO
}

\begin{abstract}
Objective: To critically review the advantages and disadvantages of selective versus comprehensive Primary Health Care $(\mathrm{PHC})$ approaches as a strategy towards improving health in the developing world.

Data sources: Review of literature on PHC.

Data selection: Relevant papers from western and developing world literature.

Data extraction: Search of Pub-med, WHO/UNICEF reports, and relevant publications on PHC.

Data synthesis: Examination of principles behind $\mathrm{PHC}$ and practical experiences in PHC in the developing world.

Conclusions: Selective PHC programs have improved specific aspects of health, frequently at the expense of other health sectors, but fail to address an individual's health in holistic manner, or the health infrastructure of countries. Selective PHC programs tend to focus only on a small subset of the community. Comprehensive PHC is expensive to implement, however addresses health of individuals more holistically, addresses both preventive and curative health care, and promotes health infrastructure development and community involvement, thereby providing more sustainable improvement of health in the whole community.
\end{abstract}

\section{INTRODUCTION}

Twenty years after the introduction of the concept of Primary Health Care (PHC) the question as to whether selective or comprehensive $\mathrm{PHC}$ is the better approach to improving health currently in the developing world has remained controversial. This paper highlights some of the advantages and disadvantages of the two approaches with some reference to experiences in countries in which they have been tried.

Primary Health Care (PHC) is defined as essential health care based on practical, scientifically sound and socially acceptable methods and technology, made universally accessible to individuals and families in the community through their full participation, and at a cost that the community and country can afford to maintain at every stage of their development in the spirit of selfreliance and self-determination(1). PHC was endorsed at an International Conference on PHC held at Alma Ata in 1978 with representatives of 134 governments and 67 international organizations in attendance(1).

PHC was initially intended to be comprehensive, to cover food supply, proper nutrition, adequate safe water and basic sanitation, health education in prevention and control of prevailing health problems, maternal and child health, immunization, prevention and control of endemic diseases, treatment of common diseases and essential drugs(1). Soon after its introduction however, there emerged a divergence of opinion on how far PHC could be implemented, and strong advocates for a selective, "less expensive, more easily attainable" approach succeeded in convincing much of the donor community to support introduction of a selective version of PHC in many developing countries(2).

Selective Primary Health Care: Selective PHC (SPHC) appeared advantageous because it advocated prioritization of conditions of most importance (of high prevalence, morbidity and mortality) and consideration of only interventions of "proven cost-effectiveness" such as growth monitoring, oral rehydration therapy (ORT) for childhood diarrhoea, breastfeeding and immunization against common childhood diseases. Such programs could be more easily and quickly implemented, and have a more visible measurable effect on child survival than the more expensive and complex comprehensive PHC. Governments and collaborating donor organizations could concentrate the limited available resources on these select programs as an interim measure and later include other "lower priority" aspects of comprehensive PHC in phases as funds became available(2).

Some countries have indeed experienced significant reduction in under-five mortality and morbidity rates under these programs. The pneumonia case-management strategy led to $2.5 \%$ reduction in pneumonia associated under-five mortality rates in six different countries(3). Programs targeting the control of diarrhoeal diseases through oral rehydration therapy and improved case management reportedly reduced diarrhoea associated 
mortality among children under-five by more than $40 \%(4,5)$. Similarly increase in breastfeeding has reduced early childhood mortality by up to six times, and morbidity by up to 18 times $(6,7)$. The expanded program of immunization (EPI) has led to increased immunization coverage by more than $50 \%$ in a majority of countries with considerable reduction in prevalence of and mortality from neonatal tetanus, diphtheria, polio, measles and severe forms of tuberculosis(8-12). Wherever ORT has been available and used appropriately it has brought about reduction in diarrhoea-specific mortality rate. However maternal understanding and practice of ORT was frequently incorrect, limiting its effectiveness. Mothers sometimes mixed home-based salt sugar solutions incorrectly, and diarrhoea morbidity and mortality actually worsened(13-15). In Zimbabwe, despite good implementation of EPI and ORT, little impact was seen on malnutrition, acute respiratory infection and diarrhoea(16).

Levels of malnutrition have risen over the past 10 years in most poor countries despite the existence of growth monitoring programs $(8,9)$. Health workers (HWs) feel ill equipped and helpless to intervene appropriately for malnourished children in the face of rising poverty and lack of food security. Family planning has successfully resulted in decline in crude birth rates to below 30 per 1000 in some countries (Peru, Egypt, Brazil). In other countries, especially in sub-Saharan Africa, crude birth rates remain above 50/1000, and little or no decline has occurred despite aggressive family planning programs. This has especially been noted in societies of high inequity and low female education, where children are seen as a resource, a source of self worth for a woman, and as a form of security for old age $(8,9,17)$.

The SPHC approach trains HWs to have a vertical narrow approach to assessment and treatment of disease, when in fact a child often presents with multiple problems. This has resulted in a dangerous tendency towards inappropriate case management, especially by lower level HWs, and has prompted the development of the new "integrated management of common childhood illness" approach (IMCI) being developed and implemented with support of the World Health Organization in the hope of correcting this problem(18).

Strong advocacy and donor support for SPHC led to donor resources targeted for health being largely restricted to these programs at the expense of other health services in some countries. Government resources tended to be re-allocated towards these programs at the expense of other health services when donor support waned. This often resulted in deterioration and sometimes collapse of such programs, as it occurred at a time of economic deterioration in the developing world. In Kenya, the immunization coverage fell from $60 \%$ to $32 \%$ between 1987 and 1997 when donors withdrew financial support for the program $(9,19)$.

SPHC has proven to be more expensive to implement than previously anticipated. Each program set up its own human organizational structure, training, supplies, storage, distribution and reporting system. Poor infrastructure hampered operations, lack of water, sanitation and food security promoted persistence of high morbidity and mortality, minimizing impact of vertical interventions(20). Sustainability has been a major problem, caused by dependence on external donor support, and the lack of complete and continuing health service infrastructure capable of reaching a majority of households and of remaining in place. Initial gains are being reversed, child mortality rates are rising, immunization rates are dropping. There is now growing disillusionment amongst recipients and donors as to whether SPHC is as "cost-effective" as it was initially advocated to be. The appropriateness of using simple technical "cost-effective" criteria to plan solutions to complex public health problems is now being questioned.

Another reality that the SPHC approach ignored is that poverty, lack of clean water, sanitation, food, and low literacy all impact health. Failure to address these factors minimises greatly the effectiveness of SPHC interventions. The health of adults (except perhaps pregnant women) has also been ignored in most SPHC programs, yet the health of a child's caretaker(s) impacts the health and well-being of the child. A sick caretaker cannot efficiently care of a child, and can pass on communicable disease to the child.

Comprehensive Primary Health Care: Comprehensive PHC (CPHC) was really understood as a strategy towards achieving "health for all" and was welcomed by most as a well thought out strategy. It is one of the few international strategies intended for the developing world that has ever sought input from experts from the developing world. It encompasses both curative and preventive aspects of health care, addresses the health of adults and children, women and men. It seeks to strengthen health care systems to facilitate efficient delivery of health care in a sustainable manner, but also seeks to harness participation of the community in caring for its own health(1).

In its entirety, CPHC required multi-sectoral action, that is, collaboration between different government sectors such as health care, education and agriculture, and this made it extremely difficult to translate it into practical activities. In reality, developing countries focused attention more on two broad areas, namely (i) Conventional medical resources were not available in rural areas - doctors and nurses were unwilling to work outside better-equipped urban health facilities and their numbers were insufficient. It was essential to train members of rural communities to deliver basic health care to their own people (community or village health workers)(ii) Most third world health problems were preventable and susceptible to elementary methods of care and simple drugs, which could be provided by increasing rural health centers and through community health workers (CHWs)(21). 
CPHC has been implemented in different ways in various developing countries such as China, Cuba, Tanzania and Guatemala. China mobilized its people at community level against endemic diseases, and through these "barefoot doctors" increased the rural population's access to health care. Although a low income country, (GNP per capita in 1980 was U.S. \$290) life expectancy improved by 20 years, infant mortality rates fell approaching those in industrialized countries, and preventive programs reduced prevalence of some infectious diseases $(9,21)$. In the early seventies Tanzania doubled its health facilities (health posts, dispensaries and health centers) and increased its trained lower cadre health staff giving priority to rural areas and emphasizing preventive health services(22). As a result, infant mortality rates fell considerably.

Some countries such as Thailand, Burma and Sri Lanka found that community health workers who volunteer and/or are selected by the community appeared to have more dedication and be more effective than those selected by a community leader or by the health system, working for predetermined wages. This appeared to work well amongst Buddhist communities where voluntarism is a positive value, and where CHWs were often already accepted by the community because of their standing as traditional healers or midwives. Efficient reliable supply of basic essential drugs to these CHWs was also fundamental to their effectiveness. A review of several different CHWs programs found that they increased the coverage and equity of service delivery at relatively low cost, but did not consistently provide services likely to have substantial health impact. Largescale CHW systems were expensive and difficult to sustain, and needed more support as an integral component of the basic health system(23).

Cuba on losing one third of its doctors after the revolution reconstructed its basic health services by building a network of health centers, and brought infant mortality rate to the lowest in Latin America(24). Costa Rica had a similar experience(21). Sri Lanka brought its infant mortality rate lower than that of India (which had a higher GNP per capita) by a PHC approach(21).

From the above experiences we learn that bringing health care closer to the people at the community level either through community based health workers, and a network of health centers which have adequate staff and a reliable supply of essential drugs, even relatively poor countries can improve health of their people. This is especially so where there is commitment towards redistribution of resources that emphasize access to health services, education and food security.

When ill, most people seek curative care, however most are less interested in preventive care activities. The effective sick service for all under the CPHC approach provides opportunity for regular contact with the bulk of the population during which to pursue preventive health care goals(25).

\section{CONCLUSION}

The burden of health care today in the third world is overwhelming, with falling GNP, smaller health budgets, and the increased burden posed on health services by AIDS. With such limited resources, governments need more than ever before to utilize their resources cost-effectively. This means being proactive in increasing preventive health care interventions in order to reduce burden of disease presenting for curative services, and harnessing the invaluable human resource of dedicated community health workers at community level to make primary care, both curative and preventive, accessible to a greater majority of households at relatively low cost. The developing world cannot afford the luxury of vertical programs. Health personnel need to be able to appropriately manage a broad base of common illnesses, and implement preventive activities targeting adults and children alike. Procurement, storage, transport and distribution of health supplies, and health information management all need to be integrated for more costeffective delivery of health care.

The health of children is much entwined with the health of their parents, and one cannot expect to achieve significant strides in the health of one group without the other.

PHC is not sufficient in itself to achieve sustained improvement in health. Alleviation of poverty, universal education, more equitable distribution of national resources, and reduction or cancellation of the developing world's foreign debt are all important factors in ensuring improved health for all. Without these the hope of achieving health for all in the developing world would appear to be a fading dream.

\section{REFERENCES}

1. WHO. Declaration of Alma Ata. Report on the International Conference on Primary Health Care. Alma Ata, U.S.S.R. ICPHC/ALA/78.10. 6-12 September 1978.

2. Walsh, J. and Warren, K. Selective Primary Health Care: an interim strategy for disease control in developing countries. Soc. Sci. Med. 1980; 14:145-164.

3. Sazawal S. and Black, R.E. Meta-analysis of intervention trials on case-management of pneumonia in community settings. Lancet. 1992; 340(8818):528-532.

4. Impact of the National Control of Diarrhoeal Disease Project on infant and child mortality in Dakahlia, Egypt. National Control of Diarrhoeal Diseases Project. Lancet. 1988; 2(8693): 145-148.

5. Messou, E., Sangare, S.V., Josseran, R., Le Corre, C. and Guelain, J. Effect of hygiene measures, water sanitation and oral rehydration therapy on diarrhoea in children less than five years old in the south of Ivory Coast. Bull. Soc. Pathol. Exot. 1997; 90:44-47.

6. WHO Collaborative Study Team on the Role of Breastfeeding on the Prevention of Infant Mortality, Victora CG corresponding author. Effect of breastfeeding on infant and child mortality due to infectious diseases in less developed countries: a pooled analysis. Lancet. 2000; 355:451-455. 
7. Clavano, N.R. Mode of feeding and its effect on infant mortality and morbidity. J. Trop. Paediatr. 1982; 28: 287-293.

8. State of the world's children UNICEF. Oxford University Press. 1986.

9. State of the world's children, UNICEF. Oxford University Press, 1999.

10. Babaniyi, O.A. A 10-year review of morbidity from childhood preventable diseases in Nigeria: how successful is the expanded programme on immunization (EPI)? An update. J. Trop. Pediatr. 1990; 36:306-313.

11. Sokhey, J., Kim-Farley, R.J. and Bhargava, I. The expanded programme on immunization: a decade of progress in India. Ann. Trop. Paediatr. 1989; 9:24-29.

12. Amin, R. Immunization coverage and child mortality in two rural districts of Sierra Leone. Soc. Sci. Med. 1992; 42:15991604.

13. McDivitt, J.A., Hornik, R.C. and Carr, C.D. Quality of home use of oral rehydration solutions: results from seven HEALTHCOM sites. Soc. Sci. Med. 1994; 38:1221-1234

14. Ekanem, E.E., Akitoye, C.O., Adedeji, O.T. and Salako, Q.A. A quantitative assessment of the Nigerian mothers' ability to prepare salt-sugar solution for the home management of diarrhoea. J. R. Soc. Health. 1993; 5:243-246

15. Islam, M.A., Kofoed, P.E. and Begum, S. Can mothers safely prepare labon-gur salt sugar solution after demonstration in a diarrhoeal hospital? Trop. Geog. Med. 1992; 44(1-2): 81-85.
16. Tumwine, J.K. and Mackenzie, S. Child survival in a rural Zimbabwe; are we winning? Cent. Afr. J. Med. 1992; 38: 30-36.

17. Mauldin, W.P. Patterns of fertility decline in developing countries, 1950-75. Stud. Fam. Plann. 1978; 9:75-84.

18. The management of childhood illness in developing countries: Rationale for an integrated strategy. W.H.O., Divison of Child Health and Development, 5 Aug. 1997 http:// www.who.int/chd/publications/imci/ration.htm

19. State of the world's children, UNICEF. Oxford University Press, 1990.

20. Briscoe, John. A role for water supply and sanitation in the child survival revolution. PAHO Bulletin. 1987; 21:93-105.

21. Walt, G. In "Caring for Health: History and Diversity" edited by Charles Webster. Revised edition 1993 Ch. 8. Open University Press, U.K.

22. Heggenhougan, K. et al. Community Health Workers: the Tanzanian Experience, Oxford University Press, 1987; p.28.

23. Berman, P.A. Gwatkin, D.R. and Burger, S. Communitybased health workers. Head start or false start towards health for all? Soc. Sci. Med. 1987; 25:443-459.

24. Riveron, C.R., Rios, N.E. and Carpio, S.R. Infant mortality in Cuba, 1969-1988. Bull. Pan. Am. Health Organ. 1989; 23:273-283.

25. Gish, O. Some links between successful implementation of primary health care interventions and the overall utilization of health services. Soc. Sci. Med. 1990; 30:401-405.

\section{EAMJ INTERNET ADDRESS}

The East African Medical Journal is now available online as well as in print. Subscribers and readers interested in viewing the Internet version may access it using the following address: http://www.bioline.org.br

The Online version is distributed by the non-profit service; Bioline Publications, a South/North partnership whose aim is to facilitate global access to bioscience and medical research publications, with emphasis on journals published in the developing world.

Subscription to the online version may be made by completing the Registration form available from the Bioline home page (http://www.bioline.org.br). Readers may take out an annual subscription or purchase single documents. Abstracts are available without registration and free of charge. 